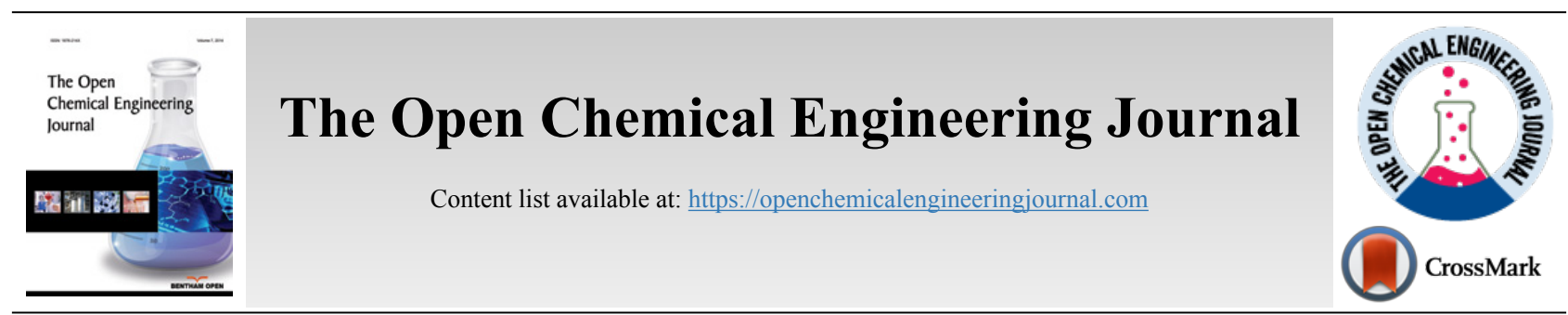

RESEARCH ARTICLE

\title{
Poly (Adenine) Modified Graphene-Based Voltammetric Sensor for the Electrochemical Determination of Catechol, Hydroquinone and Resorcinol
}

\author{
Jamballi G. Manjunatha ${ }^{1, *}$ \\ ${ }^{1}$ Department of Chemistry, FMKMC College, Madikeri, Mangalore University Constituent College, Karnataka, India
}

\begin{abstract}
:
Objective:

This paper presents the application of Poly (Adenine) Modified Graphene Paste Electrode (PAMGPE) for the analysis of Catechol (CC) with Resorcinol (RC) and Hydroquinone (HQ) by a voltammetric technique.

Methods:

Electropolymerization technique was utilized for the modification of the sensor surface. The electrode surface was characterized by Field Emission Scanning Electron Microscopy (FE-SEM). Cyclic Voltammetry (CV) and Differential Pulse Voltammetry (DPV) were used to study the redox behavior of $\mathrm{CC}, \mathrm{RC}$ and $\mathrm{HQ}$.

Results:

Oxidation peak current of $\mathrm{CC}$ increased linearly with the concentration of $\mathrm{CC}$ in the range from $2 \times 10^{-6}-8 \times 10^{-6} \mathrm{M}$ and $1 \times 10^{-5}-1.5 \times 10^{-4} \mathrm{M}$ with a detection limit of $2.4 \times 10^{-7} \mathrm{M}$. The practical application of the developed sensor was verified as exact for the determination of CC in water sample.

Conclusion:

The stability, repeatability, and reproducibility of the developed electrode were studied and established good characteristics. Furthermore, the PAMGPE was examined for the simultaneous determination of CC, RC and HQ.
\end{abstract}

Keywords: Catechol, Resorcinol, Hydroquinone, Modified electrode, Sensor, Electroanalysis.

\begin{tabular}{|l|l|l|l} 
Article History & Received: January 25, 2020 & Revised: May 08, 2020 & Accepted: May 14, 2020
\end{tabular}

\section{INTRODUCTION}

Sensitive and selective electrochemical techniques for the analysis of bioactive molecules with environmental and biological attention have been developed during the past few decades. The development of fast, sensitive, selective and correct electrochemical methods is very important for the field applications with various blocking contaminants. The voltammetric method is the best method for analyzing selective ion species [1 - 19].

Catechol (CC), resorcinol (RC), and hydroquinone (HQ) are widely used as industrial solvents. $\mathrm{CC}$ is widely used to produce food additive agents, hair dyes, and antioxidants [20]. $\mathrm{RC}$ is usually employed to produce dyes, plastics, and synthetic fibers [21 - 23]. Phenolic compounds, such as CC, RC, and HQ are found in the effluents of industries such as textile, paper and pulp, steel, petrochemical, petroleum refinery, rubber, dye,

\footnotetext{
* Address correspondence to this author at the Department of Chemistry, FMKMC College, Madikeri, Mangalore University Constituent College, Karnataka, India; Tel: +91- 08272228334; E-mail: manju1853@gmail.com
}

plastic, pharmaceutical, cosmetic, etc. and in the wastewater of synthetic coal fuel conversion processes [24, 25]. Catechol is also an important element necessary for metabolism in aromatic pollutants biodegradation [26]. Because catechol is soluble in water, it easily enters the habitat, which leads to its extensive spread in soil and water resources and thus causing a harm to nature and living organisms [27, 28]. Owing to its biotoxicity, catechol can cause lymphohematopoietic cancer, toxicity to the central nervous system, and DNA replication inhibition [29], and thus has been identified as a human carcinogen by the International Agency for Research on Cancer [30]. Therefore, the sensitive detection of catechol is of great significance for the treatment of catechol pollution and environmental monitoring. $\mathrm{CC}, \mathrm{HQ}$ and $\mathrm{RC}$ are the kinds of dihydroxy benzene isomers extensively used as raw materials and synthetic intermediates in the chemical and pharmaceutical industries [31]. Attempts have been made to study the oxidation progress of $\mathrm{HQ}, \mathrm{RC}$ and $\mathrm{CC}$ in electrochemical studies [32]. The rapid and accurate detection of these isomers in the aqueous environment is a prerequisite for their effective 
management and treatment, but in practice, it is difficult to distinguish $\mathrm{HQ}, \mathrm{RC}$ and $\mathrm{CC}$ in environmental samples because of their similar chemical structure and properties [33]. In current years, many studies reported techniques for the detection of CC, such as chromatography [34], spectrophotometry [35] and fluorescence [36]. In addition continuous development and improvement of electrochemical sensors in combination with other modifiers, such as polymers, surfactants, CNT and ionic liquids [37 - 41] have been widely reported. Although electrochemical techniques have the advantages of accuracy and rapid determination of CC, RC and HQ compounds compared to other methods that require pretreatment before testing, their operation process is complicated; expensive instrument makes them not suitable for on-site detection, especially real-time detection. These disadvantages have limited the practical application of voltammetry to a certain extent. The method proposed in this study has attracted great attention because it is simple, sensitive, and low cost and can easily realize detection. To the best of our knowledge, detection of $\mathrm{CC}, \mathrm{RC}$ and $\mathrm{HQ}$ using PAMGPE has not been investigated.

\section{MATERIALS AND METHODS}

\subsection{Chemicals}

Graphene was obtained from Tokyo Chemical Industries. $\mathrm{CC}$ and HQ were purchased from Sisco research laboratories, Mumbai, India. Silicone oil (binder) was obtained from Nice Chemical, India. Disodium hydrogen phosphate, monosodium dihydrogen phosphate and adenine were obtained from
Himedia Chemicals Company, Bangalore, India. RC was obtained from Spectrum Reagents and Chemical Pvt Ltd. Cochin, India. A stock solution of CC $\left(25 \times 10^{-4} \mathrm{M}\right)$, HQ $\left(25 \times 10^{-4} \mathrm{M}\right) \mathrm{RC}\left(25 \times 10^{-4} \mathrm{M}\right)$ and adenine $\left(25 \times 10^{-3} \mathrm{M}\right)$ was prepared by dissolving in double-distilled water. PBS was prepared by mixing a suitable amount of $0.1 \mathrm{M}$ disodium hydrogen phosphate and monosodium dihydrogen phosphate.

\subsection{Apparatus}

The electrochemical detection of $\mathrm{CC}, \mathrm{RC}$ and $\mathrm{HQ}$ was carried out using a three-electrode system connected with $\mathrm{CHI}$ $6038 \mathrm{E}$ electrochemical workstation (USA). Saturated calomel electrode was used as a reference electrode, platinum electrode as a counter electrode, BGPE and PAMGPE as working electrodes. Before starting the measurements, approximately certain amount of paste from the carbon paste electrode was wiped off by a filter paper to obtain a new surface.

\subsection{Electrode Preparation}

Bare Graphene Paste Electrode (BGPE) was prepared by mixing $60 \%$ of graphene powder and $40 \%$ of silicone oil using a mortar and pestle. After homogenization, a portion of this mixture was firmly filled into the cavity of a Teflon tube and electrical contact was made by using a copper wire. For the construction of the polymer-modified electrodes, BGPE was electrochemically activated by using ten times cyclic potential sweeps in the range from 0 to $1.6 \mathrm{~V}$ in $0.1 \mathrm{M} \mathrm{PBS} \mathrm{(pH} \mathrm{6.5)} \mathrm{at} \mathrm{a}$ scan rate of $0.1 \mathrm{Vs}^{-1}$ with $0.1 \mathrm{mM}$ adenine (Fig. 1). After electropolymerization, the modified electrode was rinsed with distilled water.

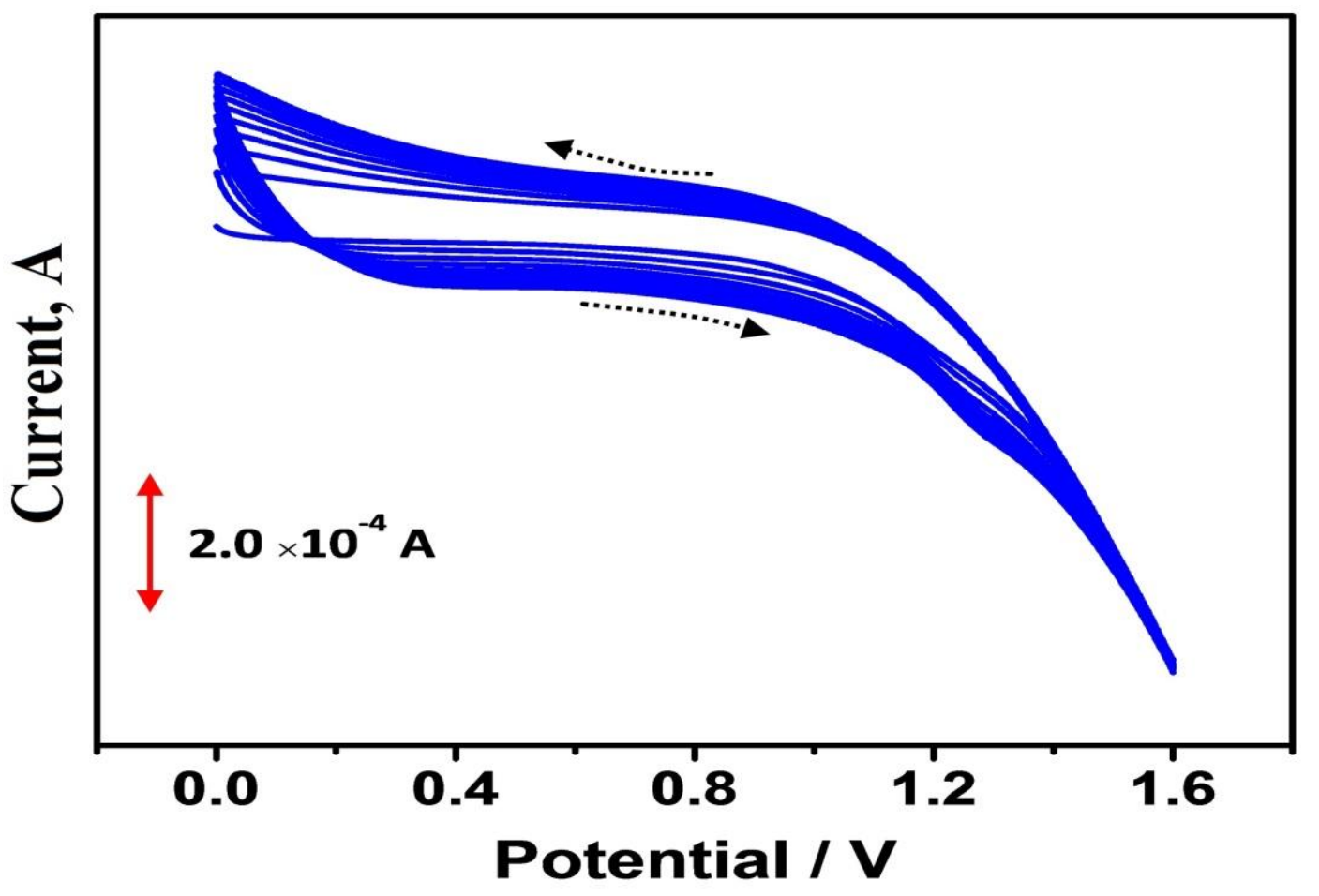

Fig. (1). Cyclic voltammograms for the electropolymerization of adenine $\left(1 \times 10^{-3} \mathrm{M}\right)$ at BGPE in $0.1 \mathrm{M} \mathrm{PBS}(\mathrm{pH} 6.5)$ at the scan rate of $0.1 \mathrm{Vs}^{-1}$. 
(a)

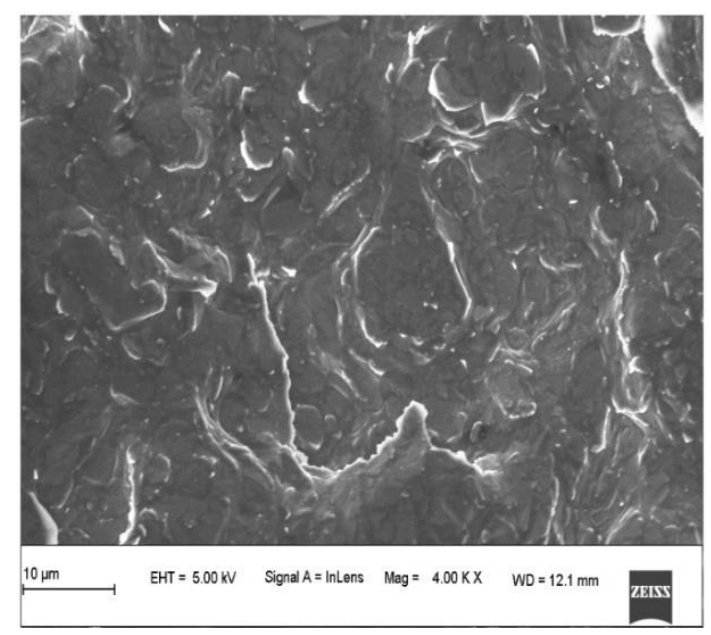

Fig. (2). FE-SEM images of (a) BGPE and (b) PAMGPE.

\section{RESULTS AND DISCUSSION}

\subsection{Morphological Characterization of BGPE and PAMGPE}

Fig. (2) shows the FESEM images of the BGPE and PAMGPE. The surface of the BGPE showed irregularly shaped graphene flakes and separated layers (Fig. 2a). The FESEM image of PAMGPE (Fig. 2b) shows the formation of a polymer layer on the BGPE surface. PAMGPE not only enlarged the surface area but also improved the electron transfer rate.

\subsection{Electrochemical Response of $\mathrm{CC}$ at PAMGPE}

The electrochemical response of $\mathrm{CC}$ was studied by performing $\mathrm{CV}$ at BGPE and PAMGPE in a solution containing $1 \times 10^{-4} \mathrm{M} \mathrm{CC}$ in $0.1 \mathrm{M}$ PBS (pH 7) with the scan rate of $0.1 \mathrm{~V} / \mathrm{s}$ Fig. (3). The CV plots of $\mathrm{CC}$ at BGPE (solid line) show an anodic peak current at $5.64 \mu \mathrm{A}$ and cathodic peak current at $4.9 \mu \mathrm{A}$. The ratio of the peak current indicates the quasi-reversible oxidation of $\mathrm{CC}$ at the electrode surface. It was also observed that the electrochemical response of $\mathrm{CC}$ at PAMGPE (dotted line) is considerably enhanced in terms of both peak current and peak shape (anodic peak current at 111.2 $\mu \mathrm{A}$, and cathodic peak at $96.9 \mu \mathrm{A}$ ) compared to BGPE. This implies that the oxidation of $\mathrm{CC}$ is more favorable on the surface of PAMGPE than BGPE.

\subsection{Electrochemical behaviors of $\mathrm{CC}$ by DPV}

Fig. (4) shows DPVs of $1 \times 10^{-4} \mathrm{M} \mathrm{CC}$ in $0.1 \mathrm{M}$ PBS (pH 7.0) at BGPE (solid line) and PAMGPE (dotted line) with the potential scan rate of $0.05 \mathrm{~V} / \mathrm{s}$. Peak current obtained at PAMGPE was much higher than the peak current obtained at BGPE. High surface area and conductivity of polymer film played an important role, which made the transfer of electrons easier.

\subsection{Electrocatalytic Oxidative Reaction of $\mathrm{CC}$}

The voltammetric behavior of $\mathrm{CC}\left(1 \times 10^{-4} \mathrm{M}\right)$ in the presence (dotted line) and absence (solid line) at PAMGPE is (b)

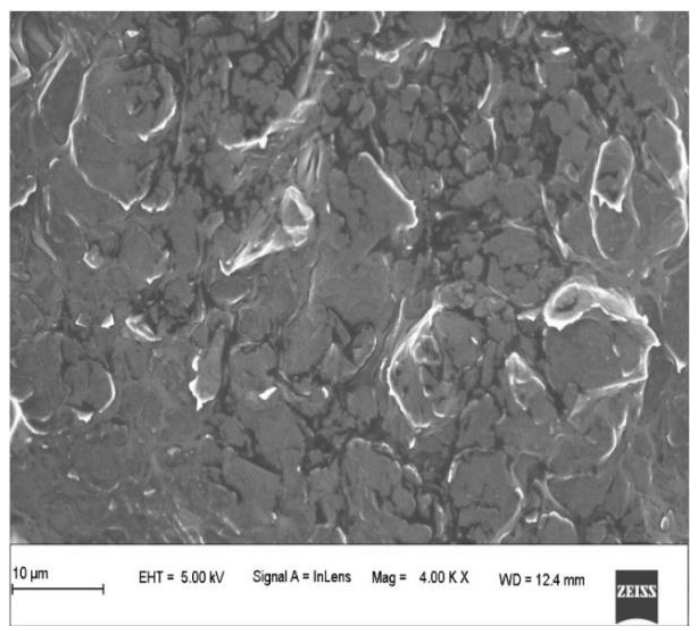

displayed in Fig. (5). The cyclic voltammograms clarify that there was no anodic peak and cathodic peak response in the case of blank, but in the presence of CC, a good voltammetric peak response was observed with the anodic peak current of $111.2 \mu \mathrm{A}$ and peak potential of $0.155 \mathrm{~V}$. This data shows that the electrocatalytic oxidative reaction depends only on $\mathrm{CC}$ at PAMGPE.

\subsection{Effect of Scan Rate on the Peak Current}

The variation in the scan rate at the peak current of $1 \times 10^{-4}$ $\mathrm{M} \mathrm{CC}$ in 0.1 M PBS (pH 7.0) was examined in the range from $0.1-0.3 \mathrm{Vs}^{-1}$ (Fig. 6a). The plot of the peak currents (Ip) against the scan rate $(v)$ exhibited a linear relationship from $0.1-0.3 \mathrm{~V} / \mathrm{s}$ with a regression equation of $\mathrm{I}_{\mathrm{pa}}(\mu \mathrm{A})=715.4 \mathrm{v}$ $\left(\mathrm{mVs}^{-1}\right)-47.26\left(\mathrm{r}^{2}=0.997\right)$ (Fig. 6B). This specifies that the electrode reaction is an adsorption controlled process. When the scan rate increased, the peak potential slightly shifted to positive values. The linear relationship between the peak potential and the logarithm of the scan rate was obtained to be $\mathrm{Ep}(\mathrm{V})=0.2297 \log \mathrm{v}\left(\mathrm{V} \mathrm{s}^{-1}\right)+0.1925 ; \mathrm{r}^{2}=0.997$ (Fig. 6c) This specifies that the electrode reaction is an adsorption controlled process.

\subsection{The Effect of Solution $\mathrm{pH}$}

The effect of solution $\mathrm{pH}$ on the electrocatalytic oxidation of $\mathrm{CC}$ at PAMGPE was studied by the $\mathrm{CV}$ technique in the $\mathrm{pH}$ range from 6.0-8.0 (Fig. 7a). With an increase in the solution $\mathrm{pH}$, anodic peak potentials shifted to negative values. This specifies that the electrocatalytic oxidation of $\mathrm{CC}$ at PAMGPE is a $\mathrm{pH}$-dependent reaction and shows that protons were involved in the electrode reaction [14]. The highest oxidation peak current was obtained at $\mathrm{pH} 7$ (Fig. 7b), after that, it decreased. $\mathrm{E}_{\mathrm{pa}}$ was proportional to the $\mathrm{pH}$ over the range from 6-8 with the linear regression equation of $\mathrm{E}_{\mathrm{pa}}(\mathrm{mV})=585-56.4$ $\mathrm{pH}$ [37], with a correlation coefficient of $\mathrm{r}^{2}=0.921$ (Fig. 7c). 


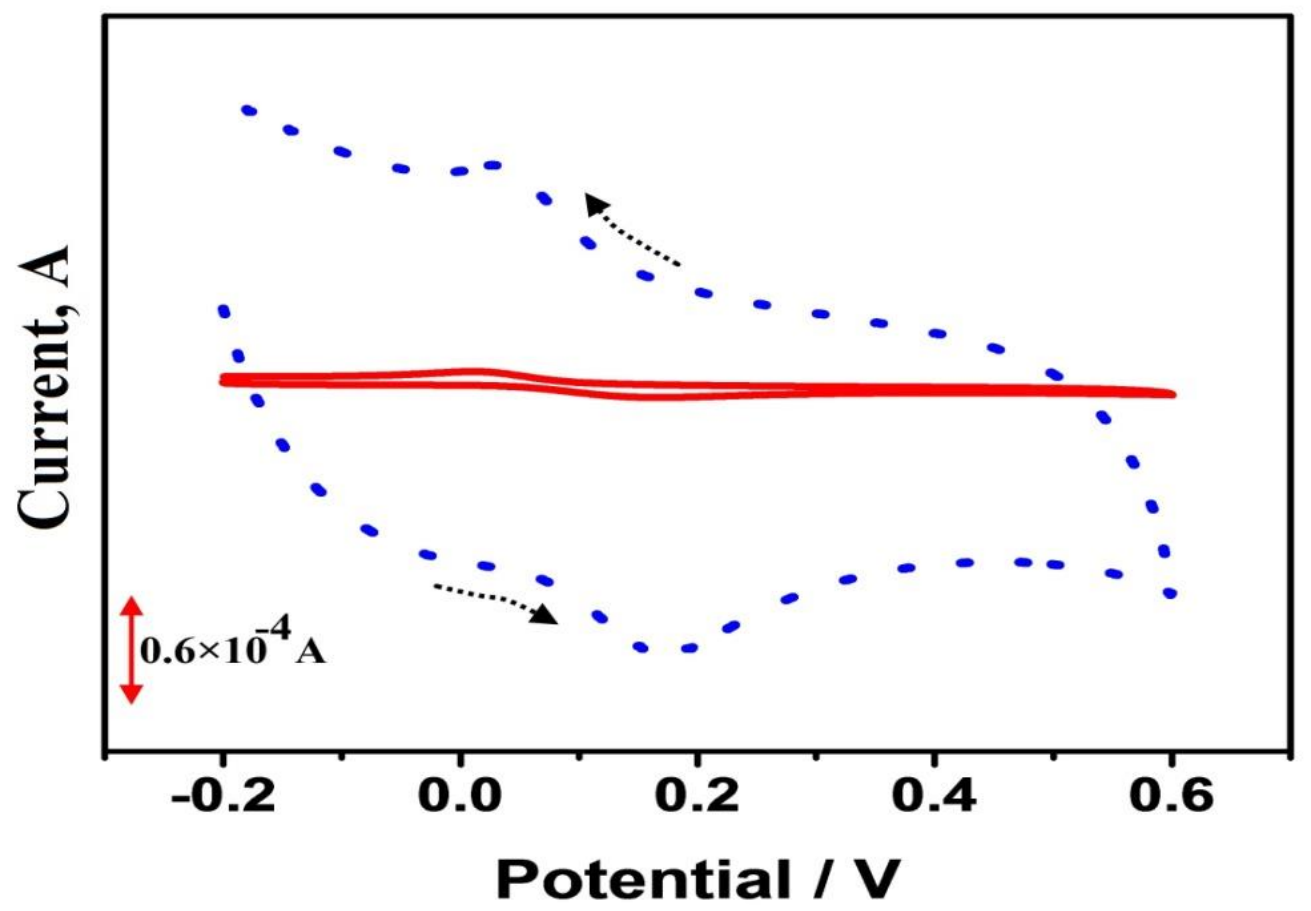

Fig. (3). Cyclic Voltammogram of $1 \times 10^{-4} \mathrm{M} \mathrm{CC}$ in $0.1 \mathrm{M}$ PBS of pH 7 at BGPE (solid line) and PAMGPE (dashed line) with the scan rate of $0.1 \mathrm{~V} / \mathrm{s}$.

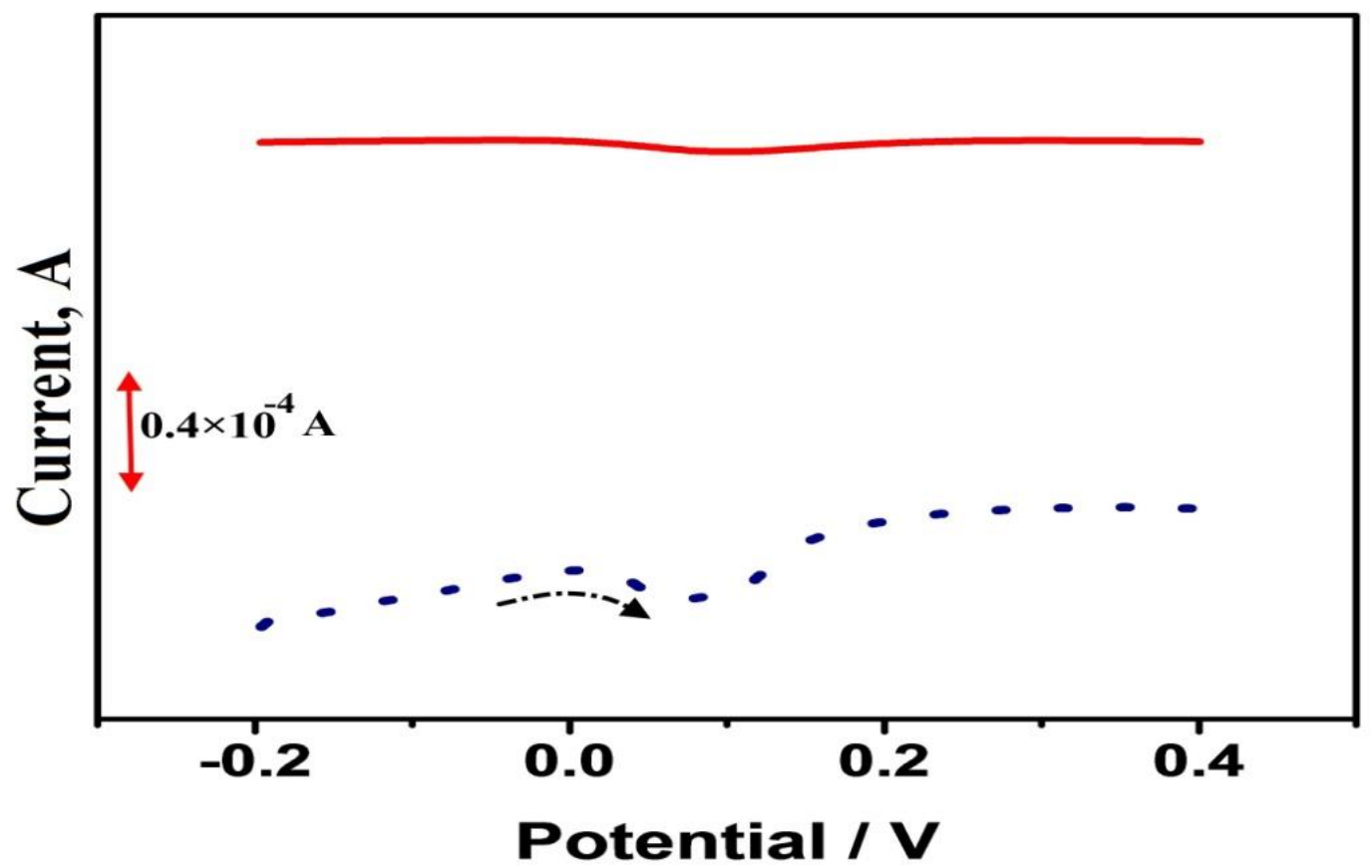

Fig. (4). DPVs of $1 \times 10^{-4} \mathrm{M} \mathrm{CC}$ in $0.1 \mathrm{M} P B S$ of $\mathrm{pH} 7$ at BGPE (solid line) and PAMGPE (dashed line) with the scan rate of $0.05 \mathrm{~V} / \mathrm{s}$. 


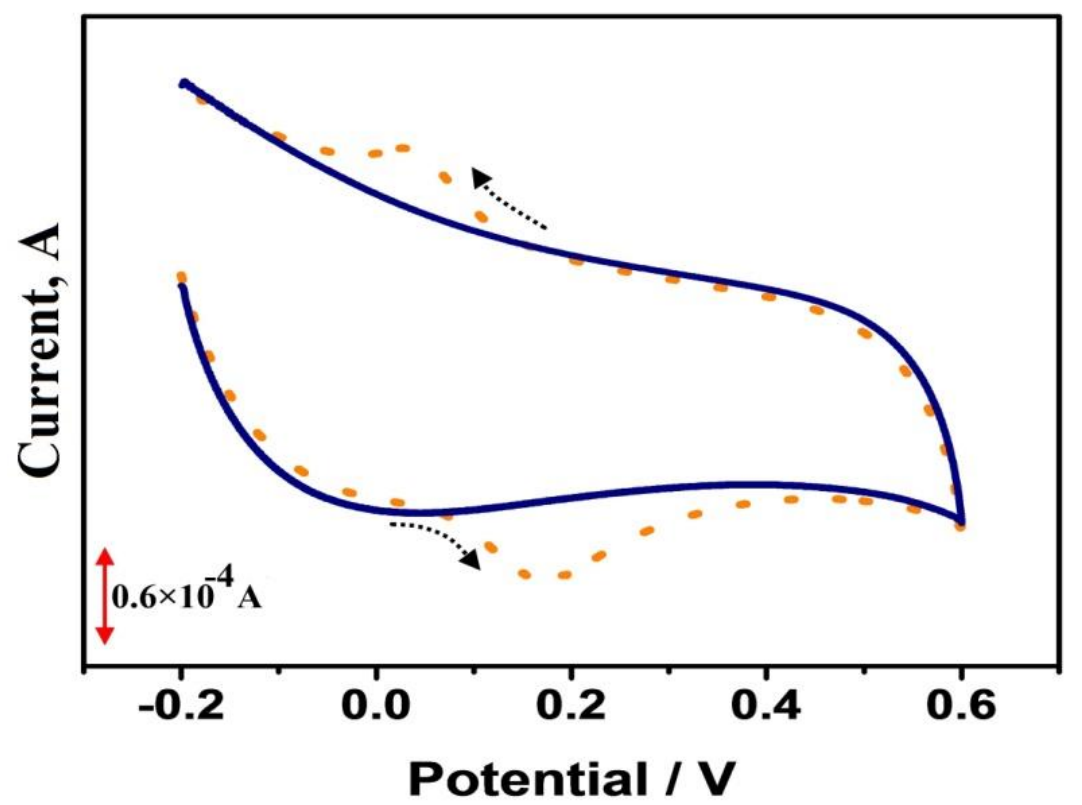

Fig. (5). Cyclic Voltammogram at PAMGPE with (dotted line) and without (solid line) $0.1 \mathrm{mM} \mathrm{CC}$ in $0.1 \mathrm{M} \mathrm{PBS}(\mathrm{pH} 7$ ) at the scan rate of $0.1 \mathrm{~V} / \mathrm{s}$.

\subsection{Repeatability, Stability, and Reproducibility}

The repeatability of the developed sensor towards CC $\left(1 \times 10^{-4} \mathrm{M}\right)$ was investigated by using three continuous measurements with the same electrode, resulting in RSDs of $2.5 \%$. This indicates the good repeatability of the developed sensor. The storage stability of the sensor was examined by intermittently measuring the peak current response of $1 \times 10^{-4} \mathrm{M}$ $\mathrm{CC}$ every ten days over one month (stored in an airtight environment at room temperature) and the response declined by $9.79 \%$ from its original response after the 30 -day storage, which specifies that the modified electrode has good stability. The reproducibility sensor was evaluated by measuring the current response of three sensors constructed independently under identical experimental conditions, and the RSD was $2.65 \%$. This shows the good reproducibility of the developed sensor.

\subsection{Responses of HQ at PAMGPE}

As shown in Fig. (8a), the sensing response of HQ at PAMGPE $(\Delta \mathrm{I}=7.6 \mu \mathrm{A})$ is $\sim 3$ times higher than that observed at BGPE $(\Delta \mathrm{I}=2.6 \mu \mathrm{A})$ and the ratio of peak current indicates the quasi-reversible oxidation of HQ at the electrode surface. Fig. (8b) shows the effect of different scan rates on HQ oxidation at PAMGPE by using CV. With the increase in the scan rate from 0.1 to $0.250 \mathrm{~V} \mathrm{~s}^{-1}$, the anodic peak current also increased linearly with the linear regression equation of $\mathrm{I}_{\mathrm{pa}}$ (A) $=1.975+0.0584 v\left(\mathrm{~V} \mathrm{~s}^{-1}\right)$ and a correlation coefficient of 0.998 (Fig. 8c). This specifies that the electrochemical reaction is consistent with the adsorption-controlled process.

\subsection{Electrochemical Behavior of $\mathrm{RC}$ at PAMGPE}

Fig. (9a) shows the cyclic voltammogram of $1 \times 10^{-4} \mathrm{M}$ of
$\mathrm{RC}$ at BGPE (dotted line) and PAMGPE (solid line) in $0.1 \mathrm{M}$ PBS ( $\mathrm{pH} \mathrm{7)}$ at the scan rate of $0.1 \mathrm{~V} / \mathrm{s}$. RC shows a weak response at $\mathrm{BGPE}$, which is 1.73 times higher than that at PAMGPE . From the graph, it is clear that the oxidation of RC is irreversible. The enhancement in $\mathrm{I}_{\mathrm{pa}}$ at PAMGPE compared with BGPE may be due to the high electron transfer kinetics, high surface area and good conductivity, which accelerate electron transfer processes between RC and PAMGPE. The influence of the potential scan rate on electrocatalytic oxidation of RC was studied by CV. As seen in Fig. (9b), with the increasing scan rate from 0.1 to $0.2 \mathrm{Vs}^{-1}$, the oxidation peak potential shifts to a more positive potential, showing the kinetic limitation in the electrochemical reaction. A linear relationship between Ip and $v$ (Fig. 9c) was observed with the linear regression equation of Ipa $(\mathrm{A})=7.096+0.037 v\left(\mathrm{~V} \mathrm{~s}^{-1}\right)$ and a correlation coefficient of 0.993 , which demonstrates that the electrode process is controlled by the adsorption.

\subsection{Simultaneous Determination of CC, RC, and HQ}

The principal target of this study was to develop a method for the simultaneous separation of $\mathrm{CC}, \mathrm{RC}$, and HQ using PAMGPE. Under the optimized conditions, the simultaneous determination of CC, RC, and HQ was studied using CV (Fig. 10). Three well-separated anodic peaks were considered at potentials of $0.044,0.179$ and $0.543 \mathrm{~V}$, which corresponded to the oxidation of $\mathrm{HQ}, \mathrm{CC}$, and $\mathrm{RC}$. The potential difference between the three anodic peak potentials of HQ, CC, and RC were $0.13,0.36$ and $0.49 \mathrm{~V}$, respectively, was high enough for the simultaneous determination of the concentration of $\mathrm{CC}$, $\mathrm{RC}$, and HQ. All three molecules' oxidation mechanisms are proposed in Scheme. (S1). 
(a)

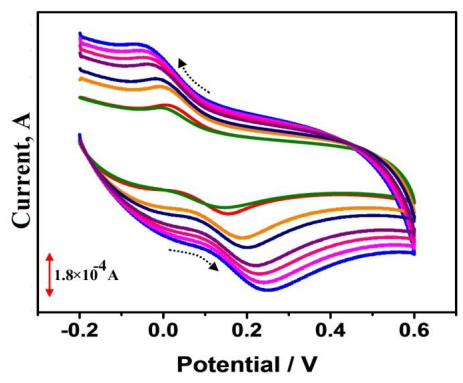

(b)

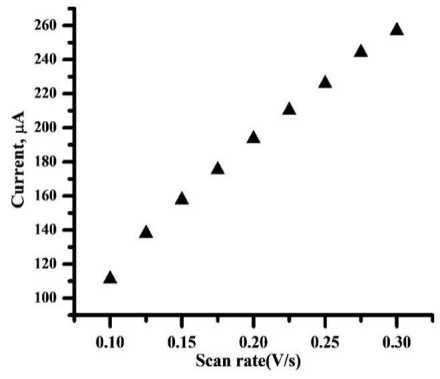

(c)

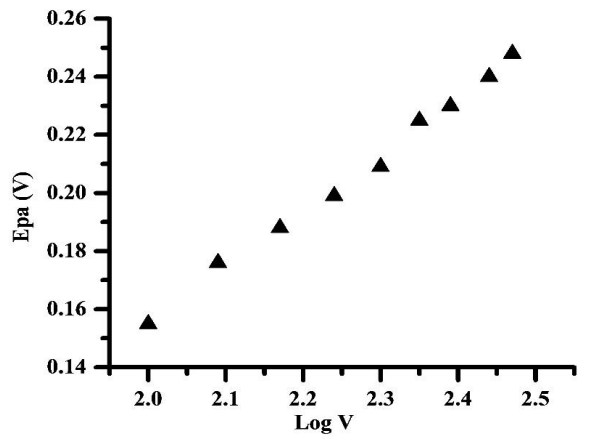

Fig. (6). (a) Cyclic Voltammogram of $0.1 \mathrm{mM} \mathrm{CC}$ at PAMGPE in $0.1 \mathrm{M}$ PBS (pH 7) at different scan rates from $0.1-0.3 \mathrm{Vs}^{-1}$, (b) $\mathrm{I}_{\mathrm{pa}} \mathrm{Vs}_{\mathrm{s}} \mathrm{scan}$ rate $\left(\mathrm{Vs}^{-1}\right),(\mathbf{c}) \mathrm{E}_{\mathrm{pa}} \mathrm{Vs}$ logarithm of scan rate $\left(\mathrm{Vs}^{-1}\right)$.

(a)

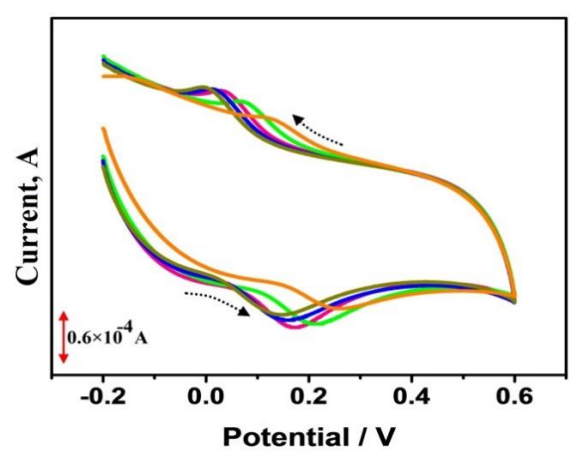

(b)

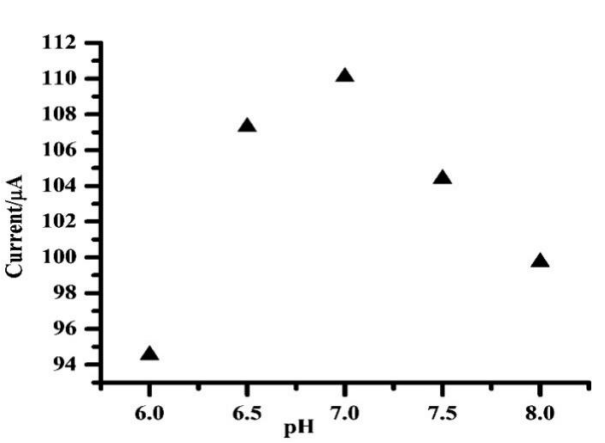

(c)

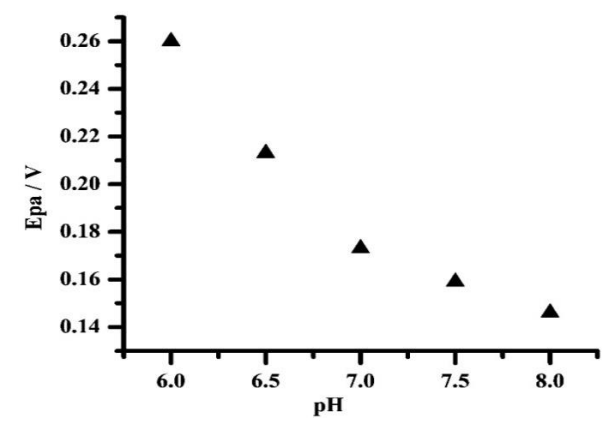

Fig. (7). (a) Cyclic Voltammogram of $0.1 \mathrm{mM} \mathrm{CC}$ at PAMGPE in $0.1 \mathrm{M}$ PBS at different $\mathrm{pH}(6.5-8.0)$ with the sweep rate of $100 \mathrm{mV} / \mathrm{s}$, (b) Ipa Vs $\mathrm{pH}$, (c) $\mathrm{E}_{\mathrm{pa}} \mathrm{Vs} \mathrm{pH}$. 
(a)

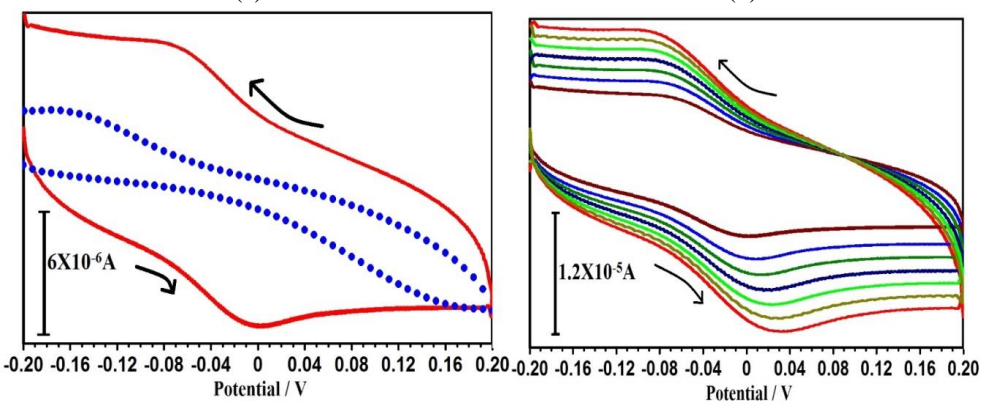

(b)

(c)

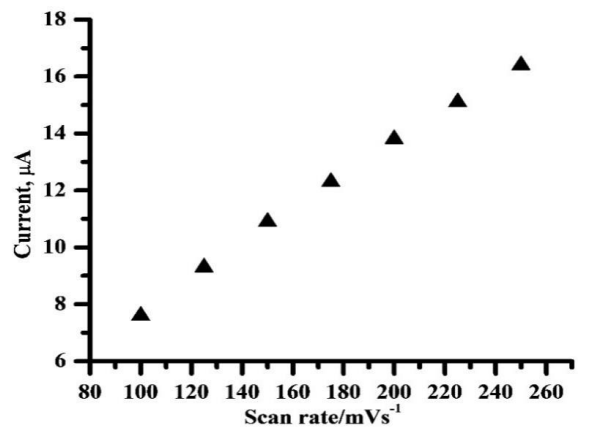

Fig. (8). (a) Cyclic Voltammogram for $0.1 \mathrm{mM}$ of HQ in $0.1 \mathrm{M}$ PBS (pH 7) at BGPE (dashed line) and PAMGPE (solid line) with the scan rate of 0.1 $\mathrm{V} / \mathrm{s}$, (b) Cyclic Voltammogram of HQ at PAMGPE in $0.1 \mathrm{M} \mathrm{PBS}(\mathrm{pH} 7)$ at different scan rates $\left(0.1\right.$ to $0.250 \mathrm{~V} \mathrm{~s}^{-1)}$, (c) Ipa Vs scan rate (mVs $\left.{ }^{-1}\right)$.

(a)

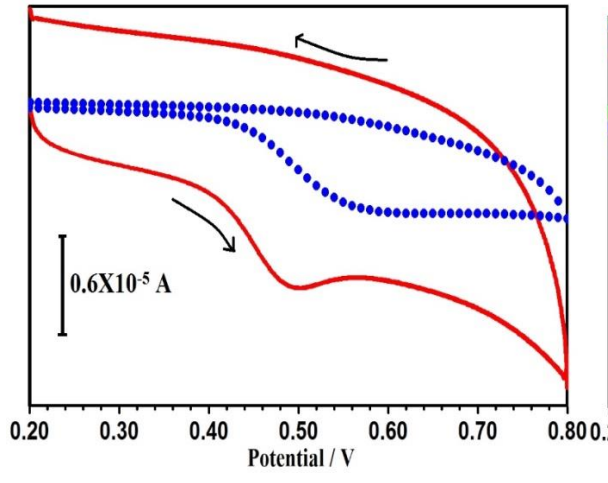

(b)

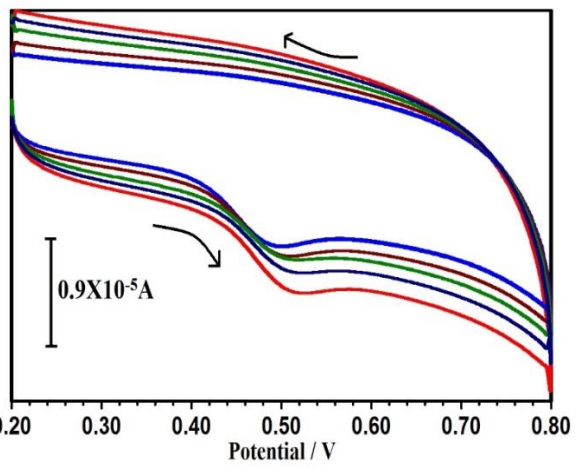

(c)

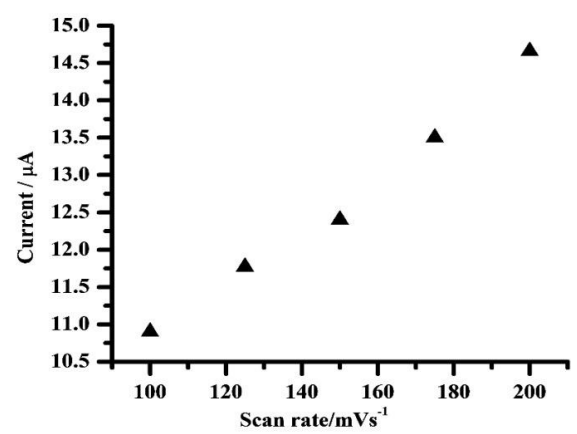

Fig. (9). (a) Cyclic Voltammogram of $1 \times 10^{-4} \mathrm{M}$ of RC in $0.1 \mathrm{M}$ PBS (pH 7) at BGPE (dashed line) and PAMGPE (solid line) with the scan rate of 0.1 $\mathrm{V} / \mathrm{s}$, (b) Cyclic Voltammogram of RC at PAMGPE in 0.1 M PBS (pH 7) at different scan rates $\left(0.1\right.$ to $0.200 \mathrm{~V} \mathrm{~s}{ }^{-1)}$, (c) Ipa Vs Scan rate. 


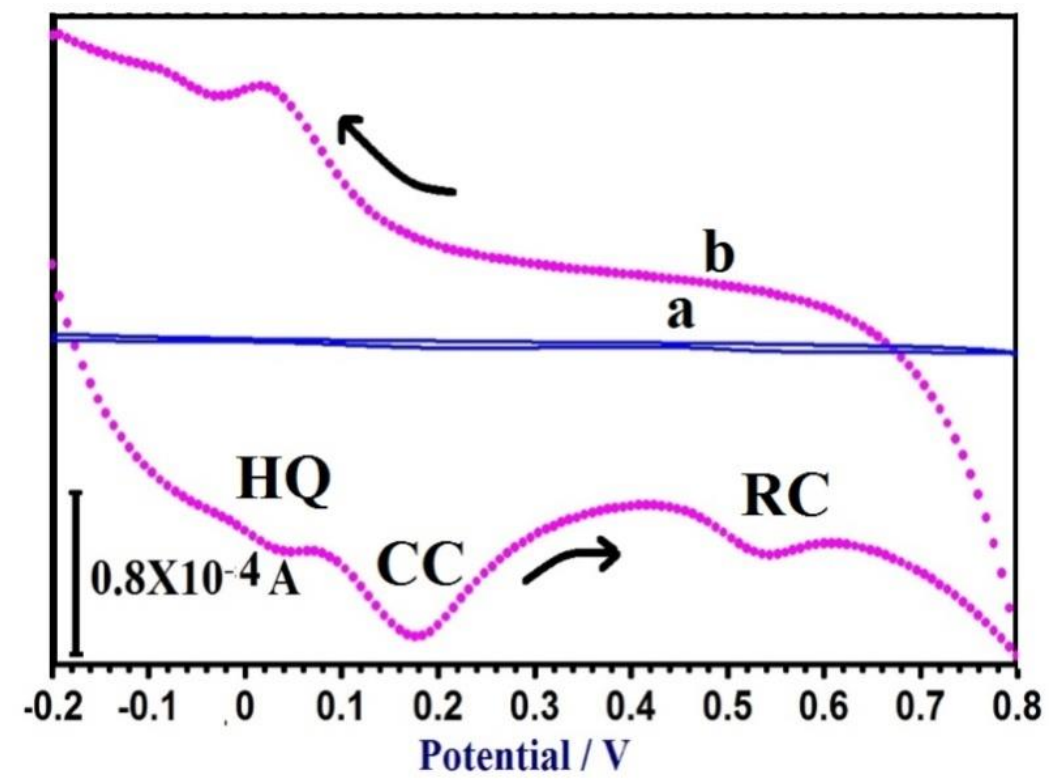

Fig. (10). Cyclic Voltammogram exhibited for simultaneous electrochemical oxidation of CC, HQ, and RC at (a) BGPE and (b) PAMGPE.

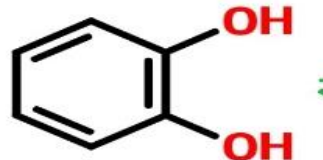

Catechol<smiles>Oc1ccc(O)cc1</smiles>

Hydroquinone

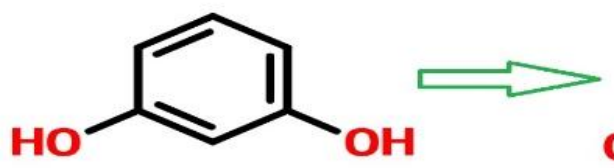

Resorcinol

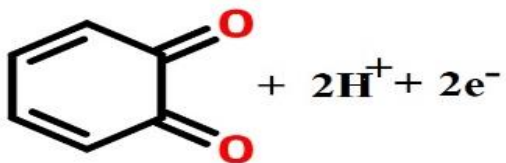

1,2 Benzoquinone<smiles>[C-][P+]#[C+]C=C1C=CC(=O)C=C1</smiles>

1,4 Benzoquinone

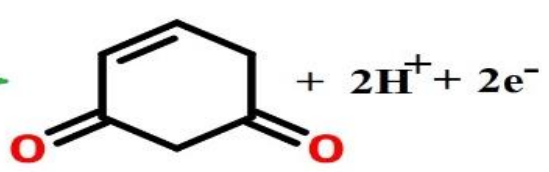

1,3 Benzoquinone

Scheme (1). Electrochemical oxidation mechanisms of CC, RC, and HQ.

\subsection{Influence of CC Concentration}

Graphene paste electrode modified with poly (adenine) indicated a significant increase in voltammetric sensitivity. CV was conducted by successively adding aliquots to the electrochemical cell. The analytical curve was obtained by the two linearities over the concentration range from $2 \times 10^{-6}-8$ $\times 10^{-6} \mathrm{M}$ and $1 \times 10^{-5}-1.5 \times 10^{-4} \mathrm{M}$. The correlation coefficient (r) was 0.993 and 0.991 with a (Fig. 11) standard deviation (SD) of $5.303 \times 10^{-7}$ and $1.726 \times 10^{-7}$, respectively. The linear regression equation was obtained to be; $\mathrm{I}_{\mathrm{pa}}$ (A) = $8.10 \times 10^{-5}+1.460 \mathrm{C}(\mathrm{M})$. Using the relation $3 \mathrm{SD} / \mathrm{m}$ and 10 $\mathrm{SD} / \mathrm{m}$ (where, $\mathrm{SD}$ is the standard deviation of the blank solution and $\mathrm{m}$ is the voltammetric sensitivity of the curve), the obtained values of limit of detection (LOD) and limit of quantification (LOQ) were $2.4 \times 10^{-7} \mathrm{M}$ and $9.1 \times 10^{-7} \mathrm{M}$. Comparisons of the results from the different published paper methods are shown in Table 1 [42 - 50]. 


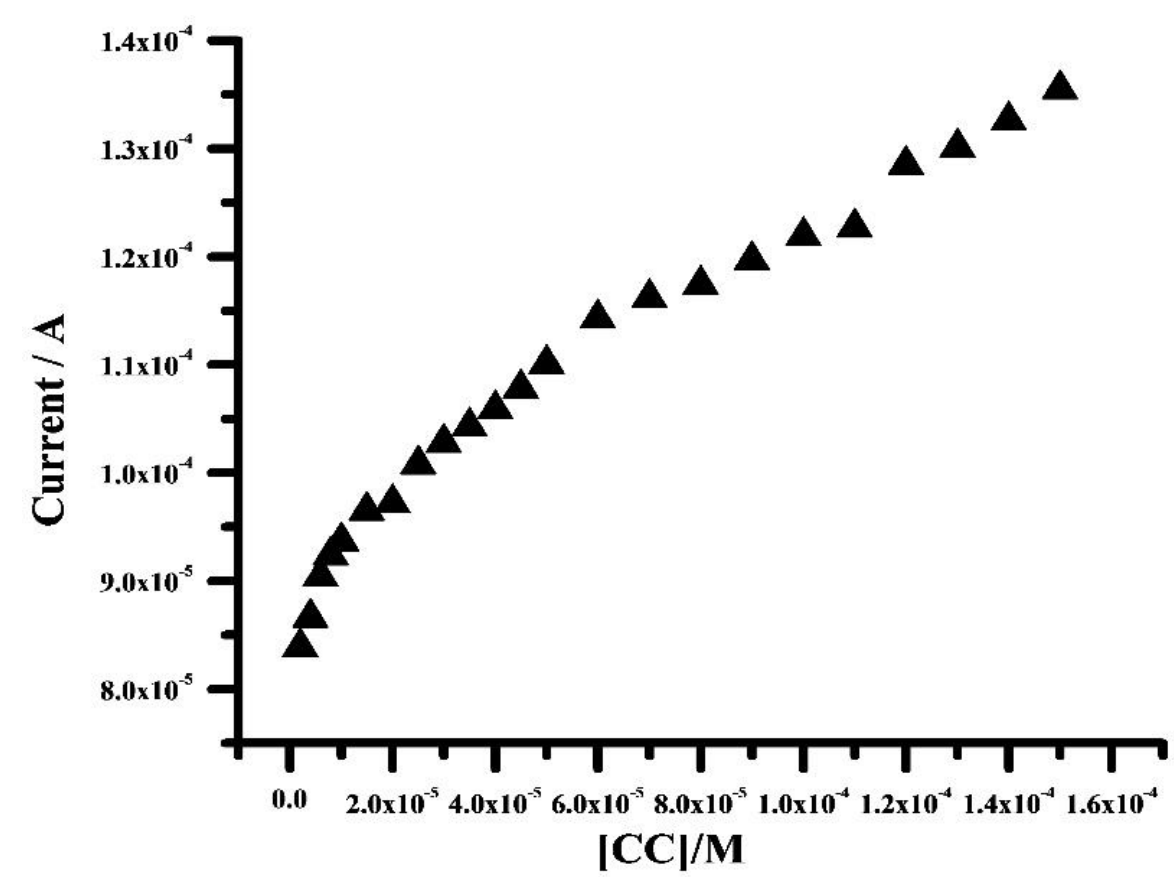

Fig. (11). A plot of anodic peak current versus concentration of CC over the range from $2 \times 10^{-6} \mathrm{M}$ to $1.5 \times 10^{-4} \mathrm{M}$.

Table 1. Comparison of PAMGPE with the few previously reported modified electrodes for the detection of $\mathrm{CC}$.

\begin{tabular}{|c|c|c|c|}
\hline Working Electrode & Limit of Detection & Method & References \\
\hline & In $\boldsymbol{\mu M}$ & & \\
\hline RGO-MWNTs & 1.8 & DPV & {$[42]$} \\
\hline MWCNT-NF-PMG/GCE & 31 & $\mathrm{CV}$ & {$[43]$} \\
\hline Influence of micelles/GCE & 3 & DPV & {$[44]$} \\
\hline $\mathrm{CNx} / \mathrm{GCE}$ & 2.71 & $\mathrm{LSV}$ & {$[45]$} \\
\hline$[\mathrm{Cu}(\mathrm{Sal}-\beta-\mathrm{Ala})(3,5-$ & 3.5 & $\mathrm{DPV}$ & {$[46]$} \\
\hline DMPz) 2$] / \mathrm{MWCNTs} / \mathrm{GCE}$ & & & \\
\hline $\mathrm{LDHf} / \mathrm{GCE}$ & 9 & $\mathrm{DPV}$ & {$[47]$} \\
\hline Poly(glycine) MGPE & 0.87 & $\mathrm{CV}$ & {$[48]$} \\
\hline Poly(methionine) MCPE & 55.66 & $\mathrm{CV}$ & {$[49]$} \\
\hline Eosin Y/CPE & 0.27 & $\mathrm{CV}$ & {$[50]$} \\
\hline Poly (adenine) MGPE & 0.24 & $\mathrm{CV}$ & This work \\
\hline
\end{tabular}

\subsection{Analytical Applications}

To prove the applicability of the modified electrode for the determination of CC, PAMGPE was applied for the determination of $\mathrm{CC}$ in the water sample. The $\mathrm{CC}$ measurement was performed by applying the proposed modified electrode in real sample solution at $\mathrm{pH} 7$ using $\mathrm{CV}$. The recoveries were obtained in the range from 92.04 to $98.5 \%$, revealing that the modified electrode was very effective for the determination of $\mathrm{CC}$ in the water sample with a good recovery rate.

\section{CONCLUSION}

In this work, PAMGPE was developed for the determination of CC, RC and HQ. Peak current enhancement and reduced peak potential were observed at the modified electrode. A brief comparison of this work with other electroanalytical methods was reported. The proposed PAMGPE has many advantages such as easy preparation, realtime sample analysis without pretreatment, good stability, and enhanced selectivity. Moreover, in comparison with the other procedures, the PAMGPE indicated good results in terms of selectivity, sensitivity and the detection limit.

\section{CONSENT FOR PUBLICATION}

Not applicable.

\section{AVAILABILITY OF DATA AND MATERIALS}

Not applicable.

\section{FUNDING}

None.

\section{CONFLICT OF INTEREST}

The authors declare no conflict of interest, financial or otherwise.

\section{ACKNOWLEDGEMENTS}

Declared none.

\section{REFERENCES}

[1] S.Z. Mohammadi, H. Beitollahi, and H. Fadaeian, "Voltammetric Determination of isoproterenol using a Graphene Oxide Nano Sheets Paste Electrode", J. Anal. Chem., vol. 73, pp. 705-712, 2018. [http://dx.doi.org/10.1134/S1061934818070122]

[2] H. Beitollahi, S. Mohadeseh, and T. Somayeh, "Application of Graphene and Graphene Oxide for modification of electrochemical sensors and biosensors: A review", Int. J. Nanodimens., vol. 10, pp. 125-140, 2019.

[3] H. Beitollahi, M. Hamzavi, and M. Torkzadeh-Mahani, "Electrochemical determination of hydrochlorothiazide and folic acid 
in real samples using a modified graphene oxide sheet paste electrode", Mater. Sci. Eng. C, vol. 52, pp. 297-305, 2015. [http://dx.doi.org/10.1016/j.msec.2015.03.031] [PMID: 25953571]

[4] H. Beitollahi, D. Gholamreza, M.H. Mahmoudi, and F. Hamid, "A sensitive electrochemical dna biosensor for anticancer drug topotecan based on graphene carbon paste electrode", J. Electrochem. Soc., vol. 164, pp. 812-817, 2017.

[http://dx.doi.org/10.1149/2.0511712jes]

[5] J.G. Manjunatha, B.E. Kumara Swamy, and M. Deraman, "Electrochemical studies of dopamine, ascorbic acid and their simultaneous determination at a poly (rosaniline) modified carbon paste electrode: a cyclic voltammetric study", Anal. Bioanal.Electrochem, vol. 5, pp. 426-438, 2013

[6] J.G. Manjunatha, B.E. Kumara Swamy, M. Deraman, and G.P. Mamatha, "Simultaneous voltammetric measurement of ascorbic acid and dopamine at poly (vanillin) modified carbon paste electrode: A cyclic voltammetric study", Pharma Chem., vol. 4, pp. 2489-2497, 2012 .

[7] J.G. Manjunatha, M. Deraman, and N.H. Basri, "Electrocatalytic detection of dopamine and uric acid at poly (basic blue b) modified carbon nanotube paste electrode", Asian J. Pharm. Clin.Res., vol. 8, pp. 48-53, 2015 .

[8] J.G.G. Manjunatha, "A novel poly (glycine) biosensor towards the detection of indigo carmine: A voltammetric study", Yao Wu Shi Pin Fen $X i$, vol. 26, no. 1, pp. 292-299, 2018. [http://dx.doi.org/10.1016/j.jfda.2017.05.002] [PMID: 29389566]

[9] J.G. Manjunatha, "Electroanalysis of estriol hormone using electrochemical sensor", Sens. Biosensing Res., vol. 16, pp. 79-84, 2017.

[http://dx.doi.org/10.1016/j.sbsr.2017.11.006]

[10] J.G. Manjunatha, "Highly Sensitive Polymer based Sensor for Determination of the Drug Mitoxantrone", J. Surface Sci. Technol, vol. 34, pp. 74-80, 2018.

[http://dx.doi.org/10.18311/jsst/2018/15838]

[11] J.G. Manjunatha, M. Deraman, N.H. Basri, and I.A. Talib, "Selective detection of dopamine in the presence of uric acid using polymerized phthalo blue film modified carbon paste electrode", Adv. Mat. Res., vol. 895 , pp. $447-451,2014$

[http://dx.doi.org/10.4028/www.scientific.net/AMR.895.447]

[12] J.G. Manjunatha, M. Deraman, N.H. Basri, and I.A. Talib, "Fabrication of poly (Solid Red A) modified carbon nanotube paste electrode and its application for simultaneous determination of epinephrine, uric acid and ascorbic acid", Arab. J. Chem., vol. 11, pp. 149-158, 2018.

[http://dx.doi.org/10.1016/j.arabjc.2014.10.009]

[13] S. Akbari, M.M. Foroughi, H.H. Nadiki, and S. Jahani, "Synthesis and characterization of $\mathrm{LaMnO} 3$ nanocrystals and graphene oxide: fabrication of graphene oxide-LaMnO3 sensor for simultaneous electrochemical determination of hydroquinone and catechol", $J$. Electrochem. Sci. Eng, vol. 9, pp. 255-267, 2019. [http://dx.doi.org/10.5599/jese.634]

[14] A. Pardakhty, M.M. Foroughi, and M. Ranjbar, "Synthesis and characterization of $\mathrm{CdO} / \mathrm{GrO}$ nanolayer for in vivo imaging", Nanomed. J., vol. 4, pp. 191-196, 2017.

[15] M.M. Foroughi, and M. Ranjbar, "Graphene oxide doped with $\mathrm{PbO}$ nanoparticles, synthesis by microwave assistant thermal decomposition and investigation of optical property", J. Cluster Sci., vol. 28 , pp. $2847-2856,2017$.

[http://dx.doi.org/10.1007/s10876-017-1248-3]

[16] M.R. Moghaddam, J.B. Ghasemi, P. Norouzi, and F. Salehnia, "Simultaneous determination of dihydroxybenzene isomers at nitrogen-doped graphene surface using fast Fourier transform square wave voltammetry and multivariate calibration", Microchem. J., vol. 145, pp. 596-605, 2019

[http://dx.doi.org/10.1016/j.microc.2018.11.009]

[17] N.M.M. Alshik Edris, J. Abdullah, S. Kamaruzaman, and Y. Sulaiman, "Voltammetric determination of hydroquinone, catechol, and resorcinol by using a glassy carbon electrode modified with electrochemically reduced graphene oxide-poly (Eriochrome black T) and gold nanoparticles", Microchim.Acta, vol. 186, 2019.

[18] M. Zhang, J. Ye, P. Fang, Z. Zhang, C. Wang, and G. Wu, "Facile electrochemical preparation of $\mathrm{NaOH}$ nanorods on glassy carbon electrode for ultrasensitive and simultaneous sensing of hydroquinone, catechol and resorcinol", Electrochim. Acta, vol. 317, pp. 618-627, 2019.

[http://dx.doi.org/10.1016/j.electacta.2019.06.006]

[19] G. Ma, H. Xu, M. Wu, L. Wang, J. Wu, and F. Xu, "A hybrid composed of MoS2, reduced graphene oxide and gold nanoparticles for voltammetric determination of hydroquinone, catechol, and resorcinol", Microchim. Acta, vol. 186, 2019

[20] B. Dellinger, W.A. Pryor, R. Cueto, G.L. Squadrito, V. Hegde, and W.A. Deutsch, "Role of free radicals in the toxicity of airborne fine particulate matter", Chem. Res. Toxicol., vol. 14, no. 10, pp. 1371-1377, 2001

[http://dx.doi.org/10.1021/tx010050x] [PMID: 11599928]

[21] Merck: The Merck Index, $11^{\text {th }}$ edn Merk, Rahway, 1989.

[22] P.W. Milligan, and M.M. Haggblom, "Biodegradation of resorcinol and catechol by denitrifying enrichment cultures", Environ. Toxicol. Chem., vol. 17, pp. 1456-1461, 1998. [http://dx.doi.org/10.1002/etc.5620170804]

[23] M.D. Hays, P.M. Fine, C.D. Geron, M.J. Kleeman, and B.K. Gullett, "Open burning of agricultural biomass: physical and chemical properties of particle-phase emissions", Atmos. Environ., vol. 39, pp. 6747-6764, 2005.

[http://dx.doi.org/10.1016/j.atmosenv.2005.07.072]

[24] A. Kumar, S. Kumar, and S. Kumar, "Adsorption of resorcinol and catechol on activated carbon: equilibrium and kinetics", Carbon, vol. 41, pp. 3015-3025, 2003.

[http://dx.doi.org/10.1016/S0008-6223(03)00431-7]

[25] N. Schweigert, A.J.B. Zehnder, and R.I.L. Eggen, "Chemical properties of catechols and their molecular modes of toxic action in cells, from microorganisms to mammals", Environ. Microbiol., vol. 3, no. 2, pp. 81-91, 2001.

[http://dx.doi.org/10.1046/j.1462-2920.2001.00176.x] [PMID: 11321547]

[26] X. Wang, Z. Gai, B. Yu, J. Feng, C. Xu, Y. Yuan, Z. Lin, and P. Xu, "Degradation of carbazole by microbial cells immobilized in magnetic gellan gum gel beads", Appl. Environ. Microbiol., vol. 73, no. 20, pp. 6421-6428, 2007.

[http://dx.doi.org/10.1128/AEM.01051-07] [PMID: 17827304]

[27] Y. Zhou, L. Tang, G. Zeng, J. Chen, Y. Cai, Y. Zhang, G. Yang, Y. Liu, C. Zhang, and W. Tang, "Mesoporous carbon nitride based biosensor for highly sensitive and selective analysis of phenol and catechol in compost bioremediation", Biosens. Bioelectron., vol. 61, pp. 519-525, 2014.

[http://dx.doi.org/10.1016/j.bios.2014.05.063] [PMID: 24951922]

[28] İ. Kara, Y. Kara, A. Öztürk Kiraz, and R. Mammadov, "Theoretical calculations of a compound formed by $\mathrm{Fe}(+3)$ and tris(catechol)", Spectrochim. Acta A Mol. Biomol. Spectrosc., vol. 149, pp. 592-599, 2015.

[http://dx.doi.org/10.1016/j.saa.2015.04.058] [PMID: 25983060]

[29] D.C. Topping, L.G. Bernard, J.L. O'Donoghue, and J.C. English, "Hydroquinone: acute and subchronic toxicity studies with emphasis on neurobehavioral and nephrotoxic effects", Food Chem. Toxicol., vol. 45 , no. 1 , pp. $70-78,2007$.

[http://dx.doi.org/10.1016/j.fct.2006.07.019] [PMID: 17030380]

[30] S. Palanisamy, K. Thangavelu, S. Chen, B. Thirumalraj, and X. Liu, "Preparation and characterization of gold nanoparticles decorated on graphene oxide@polydopamine composite: Application for sensitive and low potential detection of catechol", Sens. Actuators B Chem., vol. 233, pp. 298-306, 2016.

[http://dx.doi.org/10.1016/j.snb.2016.04.083]

[31] H. Zhang, X. Bo, and L. Guo, "Electrochemical preparation of porous graphene and its electrochemical application in the simultaneous determination of hydroquinone, catechol, and resorcinol", Sens. Actuators B Chem., vol. 220, pp. 919-926, 2015. [http://dx.doi.org/10.1016/j.snb.2015.06.035]

[32] S. Wei, D. Wang, R. Gao, and J. Kui, "Direct electrochemistry and electrocatalysis of hemoglobin in sodium alginate film on a BMIMPF6 modified carbon paste electrode", Electrochem. Commun., vol. 9, pp. 1159-1164, 2007. [http://dx.doi.org/10.1016/j.elecom.2007.01.003]

[33] M. Buleandra, A.A. Rabinca, C. Mihailciuc, A. Balan, C. Nichita, I. Stamatin, and A.A. Ciucu, "Screen-printed prussian blue modified electrode for simultaneous detection of hydroquinone and catechol", Sens. Actuators B Chem., vol. 203, pp. 824-832, 2014.

[http://dx.doi.org/10.1016/j.snb.2014.07.043]

[34] Y. Quan, Z. Xue, H. Shi, X. Zhou, J. Du, X. Liu, and X. Lu, "A highperformance and simple method for rapid and simultaneous determination of dihydroxybenzene isomers", Analyst (Lond.), vol. 137, no. 4, pp. 944-952, 2012.

[http://dx.doi.org/10.1039/C1AN15945C] [PMID: 22184582]

[35] P. Nagaraja, R.A. Vasantha, and K.R. Sunitha, "A sensitive and selective spectrophotometric estimation of catechol derivatives in 
pharmaceutical preparations", Talanta, vol. 55, no. 6, pp. 1039-1046, 2001.

[http://dx.doi.org/10.1016/S0039-9140(01)00438-6]

[PMID: 18968454]

[36] M.F. Pistonesi, M.S. Di Nezio, M.E. Centurión, M.E. Palomeque, A.G. Lista, and B.S. Fernández Band, "Determination of phenol, resorcinol and hydroquinone in air samples by synchronous fluorescence using partial least-squares (PLS)", Talanta, vol. 69, no. 5, pp. 1265-1268, 2006

[http://dx.doi.org/10.1016/j.talanta.2005.12.050] [PMID: 18970713]

[37] J. Li, J. Xia, F. Zhang, Z. Wang, and Q. Liu, "An electrochemical sensor based on copper-based metal-organic frameworks-graphene composites for determination of dihydroxybenzene isomers in water", Talanta, vol. 181, pp. 80-86, 2018.

[http://dx.doi.org/10.1016/j.talanta.2018.01.002] [PMID: 29426545]

[38] H. Wang, Q. Hu, Y. Meng, Z. Jin, Z. Fang, Q. Fu, W. Gao, L. Xu, Y. Song, and $\mathrm{F}$. Lu, "Efficient detection of hazardous catechol and hydroquinone with MOF-rGO modified carbon paste electrode", $J$. Hazard. Mater., vol. 353, pp. 151-157, 2018.

[http://dx.doi.org/10.1016/j.jhazmat.2018.02.029] [PMID: 29660701]

[39] N.F. Atta, A. Galal, and A.R.M. El-Gohary, "New insight for simultaneous determination of hazardous di-hydroxybenzene isomers at crown ether modified polymer/carbon nanotubes composite sensor", J. Hazard. Mater., vol. 388, 2020.122038

[http://dx.doi.org/10.1016/j.jhazmat.2020.122038] [PMID: 31968302]

[40] M.M. Foroughi, M. Noroozifar, and M. Khorasani-Motlagh, "Simultaneous determination of hydroquinone and catechol using a modified glassy carbon electrode by ruthenium red/carbon nanotube", J. Iran. Chem. Soc, vol. 12, pp. 1139-1147, 2015.

[http://dx.doi.org/10.1007/s13738-014-0575-7]

[41] T. Iranmanesh, M.M. Foroughi, S. Jahani, M. Shahidi Zandi, and H. Hassani Nadiki, "Green and facile microwave solvent-free synthesis of $\mathrm{CeO} 2$ nanoparticle-decorated CNTs as a quadruplet electrochemical platform for ultrasensitive and simultaneous detection of ascorbic acid, dopamine, uric acid and acetaminophen", Talanta, vol. 207, no. 120318, 2020.120318

[http://dx.doi.org/10.1016/j.talanta.2019.120318] [PMID: 31594597]

[42] J. Peng, and Z.N. Gao, "Influence of micelles on the electrochemical behaviors of catechol and hydroquinone and their simultaneous determination", Anal. Bioanal. Chem., vol. 384, no. 7-8, pp.
$1525-1532,2006$

[http://dx.doi.org/10.1007/s00216-006-0329-1] [PMID: 16505984]

[43] J. Dong, X. Qu, L. Wang, C. Zhao, and J. Xu, "electrochemistry of nitrogen-doped Carbon Nanotubes $(\mathrm{CNx})$ with different nitrogen content and its application in simultaneous determination of di hydroxyl benzene isomers", Electroanalysis, vol. 20, pp. 1981-1986, 2008.

[http://dx.doi.org/10.1002/elan.200804274]

[44] L.A. Alshahrani, X. Li, H. Luo, L. Yang, M. Wang, S. Yan, P. Liu, Y. Yang, and Q. Li, "The simultaneous electrochemical detection of catechol and hydroquinone with $[\mathrm{Cu}(\mathrm{Sal}-\beta-\mathrm{Ala})(3,5-$ DMPz)2]/SWCNTs/GCE", Sensors (Basel), vol. 14, no. 12, pp. 22274-22284, 2014.

[http://dx.doi.org/10.3390/s141222274] [PMID: 25429411]

[45] M. Li, F. Ni, Y. Wang, S. Xu, D. Zhang, and S. Chen, "Sensitive and Facile Determination of Catechol and Hydroquinone Simultaneously Under Coexistence of Resorcinol with a $\mathrm{Zn} / \mathrm{Al}$ Layered Double Hydroxide Film Modified Glassy Carbon Electrode", Electroanalysis, vol. 21, pp. 1521-1526, 2009.

[http://dx.doi.org/10.1002/elan.200804573]

[46] P.S. Ganesh, and B.E.K. Swamy, "Voltammetric investigation of catechol and hydroquinone at Triton X-100 modified carbon paste electrode", Anal.Bioanal.Electrochem, vol. 8, pp. 615-628, 2016.

[47] P.S. Ganesh, and B.E.K. Swamy, "Poly (Patton and Reeder's) modified carbon paste electrode sensor for folic acid", J. Biosens. Bioelectron., vol. 7, pp. 1-5, 2016.

[48] J.G. Manjunatha, "Electrochemical polymerised graphene paste electrode and application to catechol sensing", Open Chem. Eng. J., vol. 13 , pp. 81-86, 2019

[http://dx.doi.org/10.2174/1874123101913010081]

[49] A. Volkov, G. Tourillon, P.C. Lacaze, and J.E. Dubois, "Electrochemical polymerization of aromatic amines: IR, XPS and PMT study of thin film formation on a Pt electrode", J. Electroanal. Chem., vol. 115, pp. 279-291, 1980.

[http://dx.doi.org/10.1016/S0022-0728(80)80332-9]

[50] X. Wang, W. Tan, H. Ji, F. Liu, D. Wu, and J. Ma, "Facile electro synthesis of Nickel hexacyano ferrate/ poly (2,6-diamino pyridine) hybrids as highly sensitive nitrite sensor", Sens. Actuators B Chem., vol. 264 , pp. $240-249,2018$.

[http://dx.doi.org/10.1016/j.snb.2018.02.171]

(C) 2020 Jamballi G. Manjunatha.

This is an open access article distributed under the terms of the Creative Commons Attribution 4.0 International Public License (CC-BY 4.0), a copy of which is available at: https://creativecommons.org/licenses/by/4.0/legalcode. This license permits unrestricted use, distribution, and reproduction in any medium, provided the original author and source are credited. 